\title{
Factors associated with patients' and GPs' assessment of the burden of treatment in multimorbid patients: a cross-sectional study in primary care
}

Lilli Herzig ${ }^{1,7^{*}}$ (D) Andreas Zeller ${ }^{2}$, Jérôme Pasquier ${ }^{3}$, Sven Streit ${ }^{4}$, Stefan Neuner-Jehle ${ }^{5}$, Sophie Excoffier ${ }^{6}$ and Dagmar M Haller ${ }^{6}$

\begin{abstract}
Background: Multimorbid patients may experience a high burden of treatment. This has a negative impact on treatment adherence, health outcomes and health care costs. The objective of our study was to identify factors associated with the self-perceived burden of treatment of multimorbid patients in primary care and to compare them with factors associated with GPs assessment of this burden.

Method: A cross sectional study in general practices, 100 GPs in Switzerland and up to 10 multimorbid patients per GP. Patients reported their self-perceived burden of treatment using the Treatment Burden Questionnaire (TBQ, possible score 0-150), whereas GPs evaluated the burden of treatment on a Visual Analog Scale (VAS) from 1 to 9. The study explored medical, social and psychological factors associated with burden of treatment, such as number and type of chronic conditions and drugs, severity of chronic conditions (CIRS score), age, quality of life, deprivation, health literacy.

Results: The GPs included 888 multimorbid patients. The overall median TBQ was 20 and the median VAS was 4. Both patients' and GPs' assessment of the burden of treatment were inversely associated with patients' age and quality of life. In addition, patients' assessment of their burden of treatment was associated with a higher deprivation score and lower health literacy, and with having diabetes or atrial fibrillation, whereas GPs' assessment of this burden was associated with the patient having a greater number of chronic conditions and drugs, and a higher CIRS score.

Conclusion: Both from patients' and GPs' perspectives TB appears to be higher in younger patients. Whereas for patients the burden of treatment is associated with socio-economic and psychological factors, GPs' assessments of this burden are associated with medical factors. Including socio-economic and psychological factors on patients' self-perception is likely to improve GPs' assessments of their patients' burden of treatment thus favoring patientcentered care.
\end{abstract}

Keywords: Chronic diseases, Multimorbidity, Primary care, Burden of treatment

\footnotetext{
* Correspondence: Lilli.Herzig@hin.ch

${ }^{1}$ Department of Family Medicine, General Medicine and Public Health Centre,

University of Lausanne, Bugnon 44, 1011 Lausanne, Switzerland

${ }^{7}$ Croisettes 14, 1066, Epalinges, Switzerland

Full list of author information is available at the end of the article
}

(c) The Author(s). 2019 Open Access This article is distributed under the terms of the Creative Commons Attribution 4.0 International License (http://creativecommons.org/licenses/by/4.0/), which permits unrestricted use, distribution, and reproduction in any medium, provided you give appropriate credit to the original author(s) and the source, provide a link to the Creative Commons license, and indicate if changes were made. The Creative Commons Public Domain Dedication waiver (http://creativecommons.org/publicdomain/zero/1.0/) applies to the data made available in this article, unless otherwise stated. 


\section{Background}

Multimorbidity (commonly defined as having two or three chronic conditions) is increasing in prevalence and becoming a major health concern worldwide. [1-3] It is associated with a higher burden of disease, poorer health outcomes and reduced quality of life, more frequent hospital admissions, a higher number of provider visits, higher mortality and increasing healthcare costs. [4-8] Multimorbity is also associated with polypharmacy and its potentially negative consequences on safety of care (e.g. drug interactions). [9, 10] The prevalence of multimorbidity is high in primary care (PC) and these patients require long-term care. [11]

Physicians increasingly encourage multimorbid patients to develop self-management skills. For patients this involves finding time for health education, lifestyle changes, selfassessment and monitoring. Self-management in the context of multimorbidity has important implications for the organization of patients' daily lives. $[12,13]$ In other words, multiple chronic conditions are associated with the "work to be patient", also called burden of treatment (which is not the same as the burden of diseases). [14, 15] Burden of treatment has an impact on adherence to treatment. The higher the burden of treatment, the higher the need for patients to invest time in acquiring knowledge about their diseases and their relevant treatment options. [12, 16, 17]

Burden of treatment is a recent concept, initially introduced for single chronic conditions, and then for single chronic conditions in combination with co-morbidities. [18] It is not defined very clearly, and there are considerable variations between authors, studied populations and countries. [19, 20] To date, most studies on burden of treatment are qualitative in nature, and include the study of different aspects of daily life such as financial burden, lack of knowledge, time spent for diet and exercises, medication burden and frequent healthcare appointments. [19, 21] In 2012, based on these qualitative studies, Tran et al. proposed a quantitative measure to assess patients' self-perceived burden of treatment: the Treatment Burden Questionnaire (TBQ). [14]

Little evidence is available in relation to the factors associated with the burden of treatment for multimorbid patients in primary care. Some studies have identified physical, financial, time and psychosocial factors [19, 22, 23]. Different studies also suggest an association with socio-economic determinants and social deprivation. [16] The association between patient characteristics and burden of treatment has not been explored before. Knowledge of these factors could guide GPs in identifying patients exposed to a higher burden of treatment.

Therefore, the aim of our study was to describe the medical, psychological and socio-economic factors associated with patients' self-perceived burden of treatment. A secondary aim was to compare these factors with those associated with GPs' assessment of their patients' burden of treatment, in order to formulate hypotheses about the extent to which GPs' assessment of this burden might favor patient-centered care.

\section{Method}

Our analyses are based on the cross-sectional study "Multi-Morbidity in Family Medicine" (MMFM). The detailed study protocol and the first results have been published elsewhere. [24, 25] Briefly, MMFM included 888 multimorbid patients in primary care and involved a convenience sample of 100 GPs across five large regions in Switzerland. Eligible participants were multimorbid patients aged over 18 years old, suffering from at least three chronic conditions identified in a predefined list of 75 items based on the International Classification of Primary Care 2, (ICPC-2). [26] Each included patient gave his or her written informed consent. GPs completed a written form, whereas patients answered a standardized telephone interview conducted by trained research collaborators. Interviews were conducted in French or German depending on the region of Switzerland in which the patient lived. [24, 25]

\section{Ethical approval}

The Human Research Ethics Committee of the Canton of Vaud, acting as the lead ethics committee for Switzerland (Protocol 315/14), approved the protocol.

We evaluated the burden of treatment from two perspectives:

\section{From the patient's perspective}

We used the above-mentioned validated questionnaire, the TBQ. [14] The TBQ was first published and validated in French. We followed standard steps to create a German version: parallel translation by two professional translators, consolidation and back translation. [27] We chose the TBQ in 2013, when the protocol was established, because it was then the only existing score. We used 15 items-version of the French validation. (Additional file 1). The TBQ-score is computed by simply adding patients' answers for each item on a 10-point Likert scale. Consequently, the TBQ score ranges between 0 (no burden) and 150 (highest burden).

\section{From the GP's perspective}

GPs estimated the burden of treatment for each patient they had included on a VAS scale from 1 to 9 where 1 is the lowest and 9 the highest burden.

\section{In addition, the following variables were analyzed}

Patient's age and gender, the number of chronic conditions and drugs (as reported by GPs), the severity of chronic conditions as assessed by GPs on the 
Cumulative Illness Rating Scale (CIRS) [28], patients' quality of life (EQ. 5D 3 L) [29], their health literacy (HL score) [30], level of deprivation (DipCare score) [31]. We also examined the association between the burden of treatment and the presence of specific chronic conditions, choosing conditions that had a prevalence $>20 \%$ in our sample: hypertension (ICPC2 codes K85,86), cardiovascular risk factors (K22), diabetes (T89, 90), obesity (T82) ischemic heart diseases (K 74, 76), depression (P76) osteoarthritis of the knee (L90), general pain (A01) and atrial fibrillation (K78). (Also see results Table 1). We choose a cut-off of $20 \%$ to include the chronic conditions in the regression model in order to limit the number of variables to include with the aim to avoid overfitting.

\section{Statistical analyses}

We conducted descriptive analyses, presented as mean, standard deviation, median and interquartile range for quantitative variables and as frequencies and proportions for categorical variables.

Univariate and multivariate linear regressions were conducted to determine which factors were associated with our two outcomes, i.e. TBQ scores for the patient and VAS scores for GPs. As the TBQ was asymmetrically distributed in our sample, a logarithmic transformation of the latter was considered as the dependent variable in the regression. The GP-cluster effect was introduced into the model as a random intercept. Multiple imputations by fully conditional specification were used to handle missing values. Each missing value was imputed 15 times. To avoid overfitting, we proceeded to a forward selection of the independent variables in both multivariable regressions (TBQ and VAS). At each step of the selection, for each new variable to be included, the null hypothesis was tested that the extra parameter was zero. The variable corresponding to the smallest $p$-value was included in the model. The selection procedure was interrupted when no p-value was lesser or equal to 0.1 . As the research team suspected an association between the number of chronic conditions, the number of drugs and the CIRS (calculated as the ratio of total score/number of endorsed categories) and the burden of treatment, these variables were included in the model before starting the forward selection procedure. Finally, we computed the variance inflation factor (VIF) of the selected variables to ensure their non-collinearity.

\section{Dependent variables}

Log (TBQ score + 1), VAS scale.

\section{Independent variables}

All variables described in Table 1, except for the two dependent variables.
All analyses were conducted using $\mathrm{R}$ version 3.4.4 and the package mice version 2.46 for the imputation of missing values. [32, 33]

\section{Results}

We included 888 patients (mean age of 72.9 years, $48 \%$ were men). They had a mean of 7.2 chronic conditions (SD 2.9) and were taking a mean of 7.5 pills a day (SD 3.5) . Patients' characteristics and factors associated with the TBQ (Mean (SD), Median (IQR), Frequency and Percentage) are listed in Table 1 . We created a correlation matrix, which can be found in the additional file (Additional file 2)

\section{Patients' perspective}

The overall median TBQ score was $20(\mathrm{Q} 25 \%=15$, Q75\% = 33). The distribution is shown in Figs. 1 and 2.

The results of the regressions are shown in Table 2. The effect size is given on the logarithmic scale. The forward selection process led to the inclusion of age, education, use of a pillbox, quality of life (EQ5D3L_score and EQ5D3L VAS), DipCare index, health literacy, diabetes and atrial fibrillation in the multivariable model (as previously stated, number of chronic conditions, CIRCS (ratio total score/number of endorsed categories) and number of drugs were included in the model before the selection). Variance inflation factors were relatively low. There is thus no major collinearity between the variables introduced in the model. Younger age, higher education, higher deprivation score, lower quality of life and health literacy scores were significantly associated with higher TBQ scores. Furthermore, patients with diabetes or atrial fibrillation had higher TBQ scores. We found no association between depression (P76), general pain (A01) or the CIRCS, and TBQ scores.

\section{GPs' perspective}

The median VAS rating was $4(\mathrm{Q} 25 \%=3, \mathrm{Q} 75 \%=6)$. The results of the regressions are shown in Table 3 and the distribution is shown in Fig. 3. Forward selection resulted in the inclusion of age, use of a pillbox, homebased care, quality of life (eq5d3l score and eq5d3l VAS), health literacy, general pain and atrial fibrillation in the multivariable model (again, number of chronic conditions, CIRS and number of drugs were included in the model before the selection). We found an association between a higher VAS rating and lower age, higher number of chronic conditions and drugs, higher CIRCS and a lower quality of life score.

\section{Discussion}

Our study analyzed factors associated with multimorbid patients' self-perceived burden of treatment as well as factors associated with GPs' assessment of this burden. 
Table 1 Characteristics of the 888 included patients and main results regarding associated factors

\begin{tabular}{|c|c|c|c|c|c|}
\hline Description & Type & $\begin{array}{l}\mathrm{N} \text { missing } \\
\text { values }\end{array}$ & Value & Frequency* & Percentage* \\
\hline \multirow{2}{*}{$\begin{array}{l}\text { TBQ score } \\
\text { (patient perspective) }\end{array}$} & \multirow[t]{2}{*}{ Numeric } & \multirow[t]{2}{*}{0} & Mean/SD & 26.8 & 18.6 \\
\hline & & & Median/IQR & 20.0 & {$[15.0 ; 33.0]$} \\
\hline \multirow{2}{*}{$\begin{array}{l}\log (\text { TBQ score }+1) \\
\text { (patient perspective) }\end{array}$} & \multirow[t]{2}{*}{ Numeric } & \multirow[t]{2}{*}{0} & Mean/SD & 3.2 & 0.6 \\
\hline & & & Median/IQR & 3.0 & {$[2.8 ; 3.5]$} \\
\hline \multirow[t]{2}{*}{ VAS rating (GP perspective) } & \multirow[t]{2}{*}{ Numeric } & \multirow[t]{2}{*}{1} & Mean/SD & 4.5 & 1.7 \\
\hline & & & Median/IQR & 4.0 & {$[3.0 ; 6.0]$} \\
\hline \multirow[t]{2}{*}{ Patient's age } & \multirow[t]{2}{*}{ Numeric } & \multirow[t]{2}{*}{0} & Mean/SD & 72.9 & 12.0 \\
\hline & & & Median/IQR & 74.2 & {$[65.9 ; 81.8]$} \\
\hline Patient's gender is male & Logical & 0 & TRUE & 428 & 48.2 \\
\hline \multirow[t]{3}{*}{ Location of practice } & \multirow[t]{3}{*}{ Category } & \multirow[t]{3}{*}{0} & Urban & 383 & 43.1 \\
\hline & & & Semi-urban & 361 & 40.7 \\
\hline & & & Rural & 144 & 16.2 \\
\hline \multirow[t]{4}{*}{ Marital status } & \multirow[t]{4}{*}{ Category } & \multirow[t]{4}{*}{0} & Single & 85 & 9.6 \\
\hline & & & Married & 437 & 49.2 \\
\hline & & & $\begin{array}{l}\text { Separated/ } \\
\text { divorced }\end{array}$ & 150 & 16.9 \\
\hline & & & Widow & 216 & 24.3 \\
\hline \multirow[t]{3}{*}{ Highest level of schooling achieved } & \multirow[t]{3}{*}{ Category } & \multirow[t]{3}{*}{1} & $\begin{array}{l}\text { Compulsory } \\
\text { education }\end{array}$ & 195 & 22.0 \\
\hline & & & $\begin{array}{l}\text { Upper secondary } \\
\text { level }\end{array}$ & 337 & 38.0 \\
\hline & & & Tertiary level & 355 & 40.0 \\
\hline \multirow[t]{2}{*}{ Number of CC (GP's assessment) } & \multirow[t]{2}{*}{ Numeric } & \multirow[t]{2}{*}{4} & Mean/SD & 7.2 & 2.9 \\
\hline & & & Median/IQR & 7.0 & {$[5.0 ; 8.2]$} \\
\hline \multirow[t]{2}{*}{ CIRS } & Numeric & 1 & Mean/SD & 1.7 & 0.4 \\
\hline & & & Median/IQR & 1.7 & {$[1.5-2.0]$} \\
\hline Total number of different pharmacological treatment the patient is & Numeric & 0 & Mean/SD & 7.7 & 3.5 \\
\hline & & & Median/IQR & 7.0 & {$[5.0 ; 10.0]$} \\
\hline Use of a pillbox (dispenser) & Logical & 0 & TRUE & 405 & 45.6 \\
\hline Home-based care (patient report) & Logical & 10 & TRUE & 94 & 10.6 \\
\hline Total EQ-5D-3 L score & Numeric & 0 & Mean/SD & 69.9 & 17.6 \\
\hline & & & Median/IQR & 70.5 & {$[62.4 ; 78.3]$} \\
\hline EQ-5D-3 L health scale (VAS, 0-100) & Numeric & 0 & Mean/SD & 63.2 & 19.3 \\
\hline & & & Median/IQR & 65.0 & {$[50.0 ; 80.0]$} \\
\hline Deprivation score (DipCare) & Numeric & 0 & Mean/SD & 1.2 & 0.9 \\
\hline & & & Median/IQR & 0.9 & {$[0.5 ; 1.8]$} \\
\hline Health literacy score (HLS EU 6) & Numeric & 577 & Mean/SD & 2.9 & 0.5 \\
\hline & & & Median/IQR & 2.8 & {$[2.7 ; 3.2]$} \\
\hline Hypertension (ICPC:K85,86) & Logical & 0 & TRUE & 657 & 74.0 \\
\hline Cardiovascular risk factors (ICPC:K22) & Logical & 0 & TRUE & 391 & 44.0 \\
\hline Diabetes (ICPC: T89,90) & Logical & 0 & TRUE & 277 & 31.2 \\
\hline Obesity (ICPC: T82) & Logical & 0 & TRUE & 274 & 30.9 \\
\hline Ischemic heart disease (ICPC: K74,76) & Logical & 0 & TRUE & 258 & 29.1 \\
\hline Depression (ICPC: P76) & Logical & 0 & TRUE & 228 & 25.7 \\
\hline
\end{tabular}


Table 1 Characteristics of the 888 included patients and main results regarding associated factors (Continued)

\begin{tabular}{|c|c|c|c|c|c|}
\hline Description & Type & $\begin{array}{l}\mathrm{N} \text { missing } \\
\text { values }\end{array}$ & Value & Frequency* & Percentage $^{*}$ \\
\hline Knee osteoarthritis (ICPC:L90) & Logical & 0 & TRUE & 223 & 25.1 \\
\hline Pain general (ICPC:A01) & Logical & 0 & TRUE & 198 & 22.3 \\
\hline Atrial Fibrillation (ICPC:K78) & Logical & 0 & TRUE & 195 & 22.0 \\
\hline
\end{tabular}

Younger, educated patients, those with a lower quality of life, a higher deprivation score and lower health literacy reported higher self-perceived burden of treatment. Suffering from diabetes or atrial fibrillation was also independently associated with higher patients' self-reported burden of treatment. From the GPs' perspective, burden of treatment was also perceived to be higher in younger patients and in those suffering from atrial fibrillation. Medical factors (number of chronic conditions, number of drugs...) rather than social factors (deprivation, literacy...) appeared to be more strongly associated with GPs' perceptions of their patients' burden of treatment. GPs seemed to integrate the notion of deprivation or lower health literacy in their estimation of their patients' burden of treatment only to a minor degree.

The most important finding in our study is the association between higher burden of treatment and younger age. We hypothesize that this may be due to a higher impact of multimorbidity on an active professional life: younger patients may have more difficulties integrating the workload of treatment for several chronic conditions into an active professional life. Alternatively, older patients' self-perceived burden of treatment may be lower due to a higher acceptance of their chronic conditions with time, or as a consequence of their social education (readiness to accept a negative condition). Most previous studies on multimorbidity were conducted in older populations only and this may be the reason why our finding is new. $[1,34,35]$.
A second important finding is the difference in factors associated with burden of treatment between patients and GPs. While patients' estimates of their burden of treatment were predominantly associated with psychological and socioeconomic factors (deprivation, health literacy and lower quality of life), GPs' perspectives were more strongly associated with medical factors such as the number of chronic conditions and drugs. In order to achieve realistic goals, practice patient-centered care and apply shared decision-making care models - as proposed by Muth et al. - GPs should probably explore their patients' self-perceived burden of treatment, rather than rely only on their own assessment. [36, 37] Our results are in line with other publications showing that patientprovider concordance needs to be improved. [38, 39]

Caring for multimorbid patients is a complex task which needs an understanding beyond the simple compilation of chronic conditions or bio-medical concepts. [40] However, our study shows that GPs estimates of the burden of treatment most strongly relate to such factors. As multimorbidity is a long-term challenge and needs a paradigm change "from cure to care" or "from guidelines to mindlines" the integration and correct estimation of patients' burden of treatment is important. [11, 41] This includes patient's ability for self-management and an understanding of factors that may limit this ability, such as low health literacy. $[42,43]$ Our study shows the importance of patient-centered care: the role of GPs is to

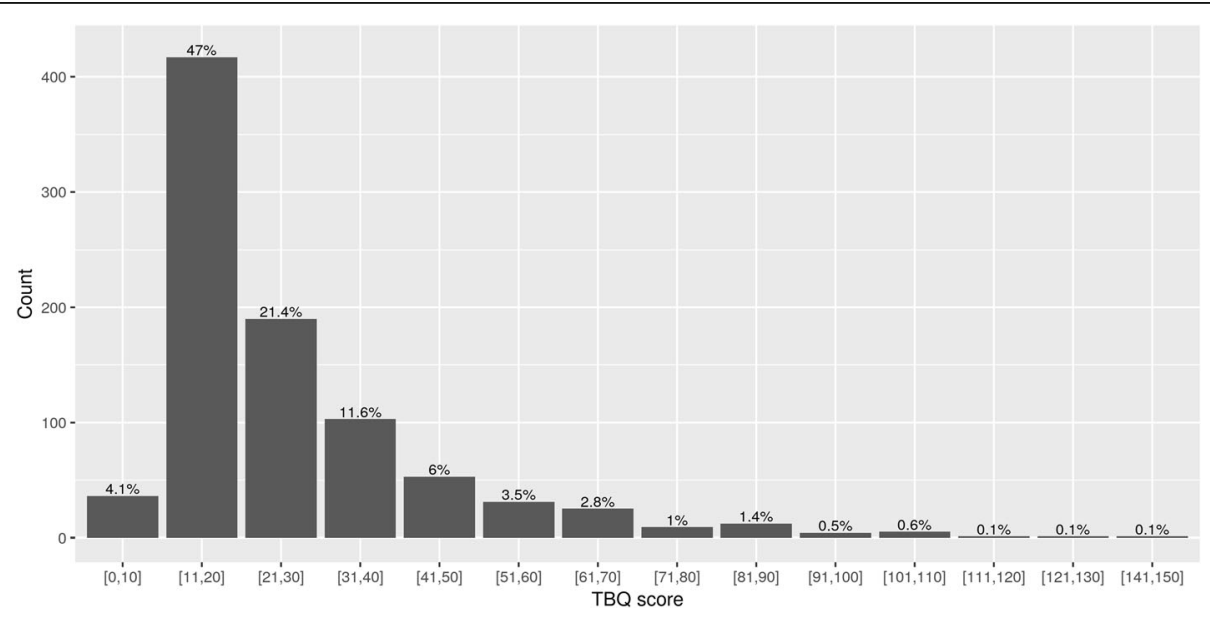

Fig. 1 Overall TBQ score 


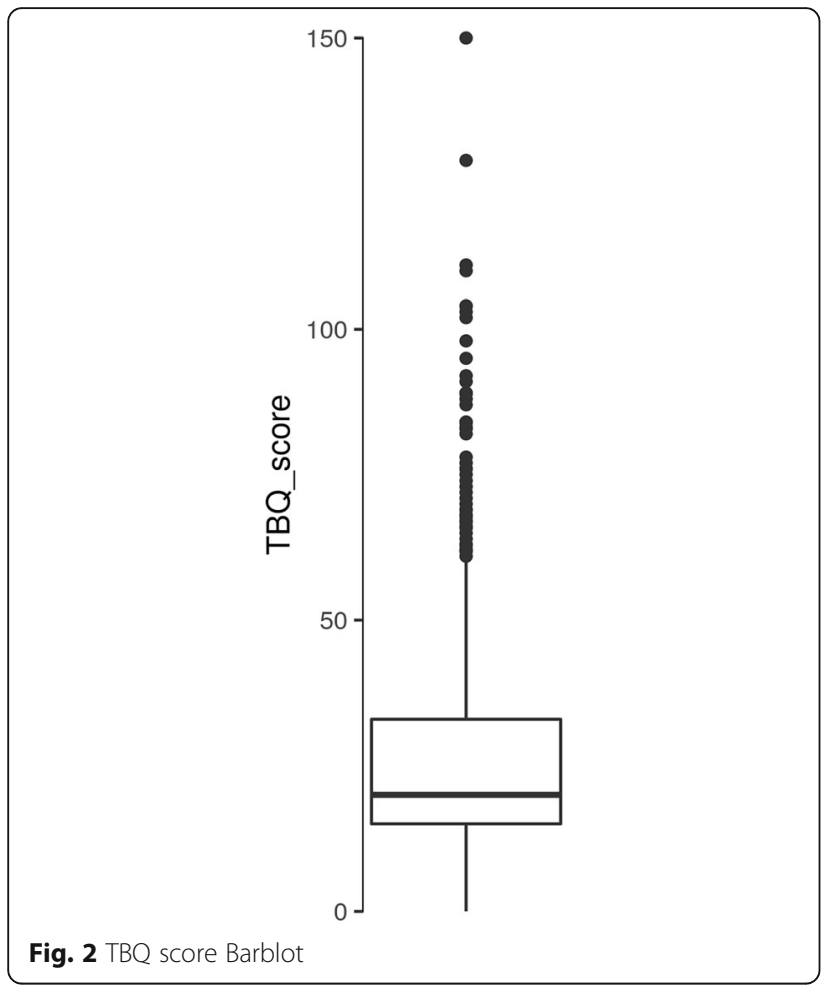

explore patients' burden and limits, including socioeconomic and psychological factors.

An important challenge is to improve treatment adherence in multimorbid patients. This has an impact on long-term outcomes and health care costs. Indeed, higher burden of treatment is associated with poorer treatment adherence. $[18,44]$ Therefore, a better understanding of factors associated with patient's ability and workload is likely to help improve treatment adherence. [40] We need to "start treatment for patients not for diseases" as proposed by May. [45] When starting new treatments, we also need to weigh the added burden of treatment against the (sometimes-small) effects of these new treatments in multimorbid patients. Therefore, for every potential treatment (e.g. recommended by a guideline), GPs should consider the potential added burden of treatment and discuss and weigh this with their patients. Evidence from the literature confirms that better knowledge of patients' needs and goals, improved relationship, patient-centered care and shared decisions between GPs and patients improve treatment adherence and patients' satisfaction as well as outcomes. [17, 46-48] Therefore, it seems essential to integrate individual patients' perceived burden of treatment into every decision about the longterm management in the context of multimorbidity.

Another finding of our study suggests that burden of treatment is particularly high for diabetic patients. Yet the literature on diabetes rarely integrates burden of treatment factors such as emotional elements, diet or food constraints, which are highly important for patients with diabetes. [17, 49] We hypothesize that the burden of treatment is particularly high for patients with diabetes because the treatment requires activities in multiple domains, e.g. daily serum glucose controls, adaptation of diet, physical exercise. This has an important impact on social life and attitudes.

Atrial fibrillation was also associated with a higher burden of treatment. This might be explained by the need for anticoagulation, which has an impact on drug and food interactions or on the number of GP visits required.

\section{Strengths}

Our study is one of the first quantitative studies to use Tran's TBQ score in a large population of multimorbid patients in primary care. Furthermore, to the best of our knowledge it is the first study to integrate factors associated with burden of treatment both from GPs' and from patients' perspectives.

Another strength is the inclusion of younger patients in our sample. Most studies on multimorbidity usually only select older patients. And our study covers a diverse sample from French and German-speaking regions, recruited over most of an entire country, thus better reflecting usual care in multimorbid patients in primary care.

Finally, our study assessed an important range of social as well as medical variables potentially associated with burden of treatment in multimorbid patients in $\mathrm{PC}$, thus covering a wide range of dimensions of the burden of treatment.

\section{Limitations}

Our study has some limitations. First the French-version of the TBQ, developed in 2012, has not been used elsewhere. We created a German version of the TBQ using careful translation-back-translation of the validated French version, but did not validate this version per-se. Furthermore, the original TBQ was developed and validated for face to face interviews and we cannot exclude some differences when using phone interviews. Because the TBQ was not developed for this purpose, and also to limit the study burden for GPs, we used a VAS to assess burden of treatment from the GPs perspective and not the TBQ. This may have had an influence on the comparison between the two perspectives. In addition, this method precluded any direct comparison between GPs' and patients' TBQ scores. Finally, there were many missing values on the health literacy score. We used multiple imputations to adjust for this, which may have influenced our findings.

\section{Conclusions}

Both from patients' and GPs' perspectives burden of treatment appears to be higher in younger patients. 


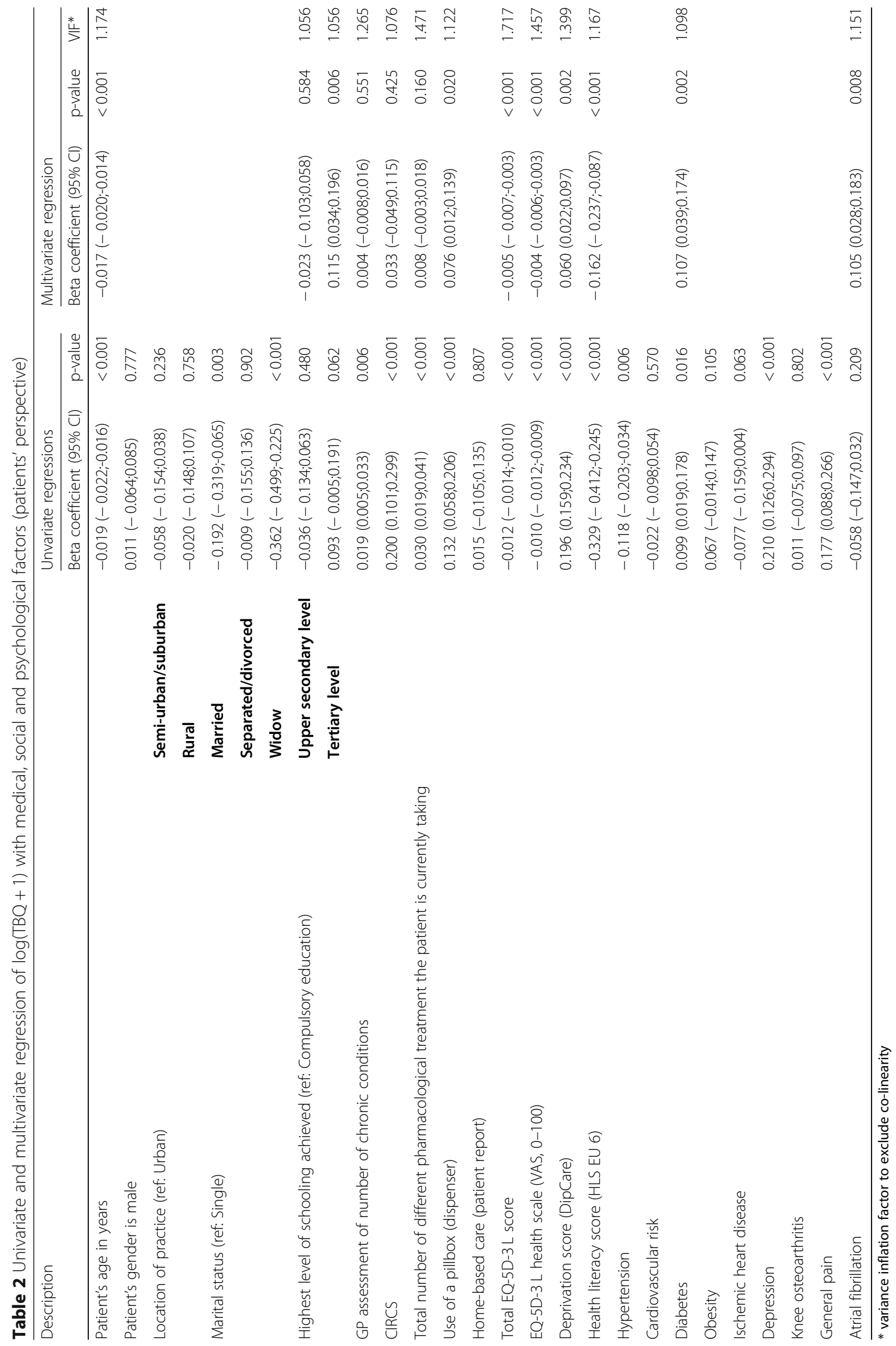




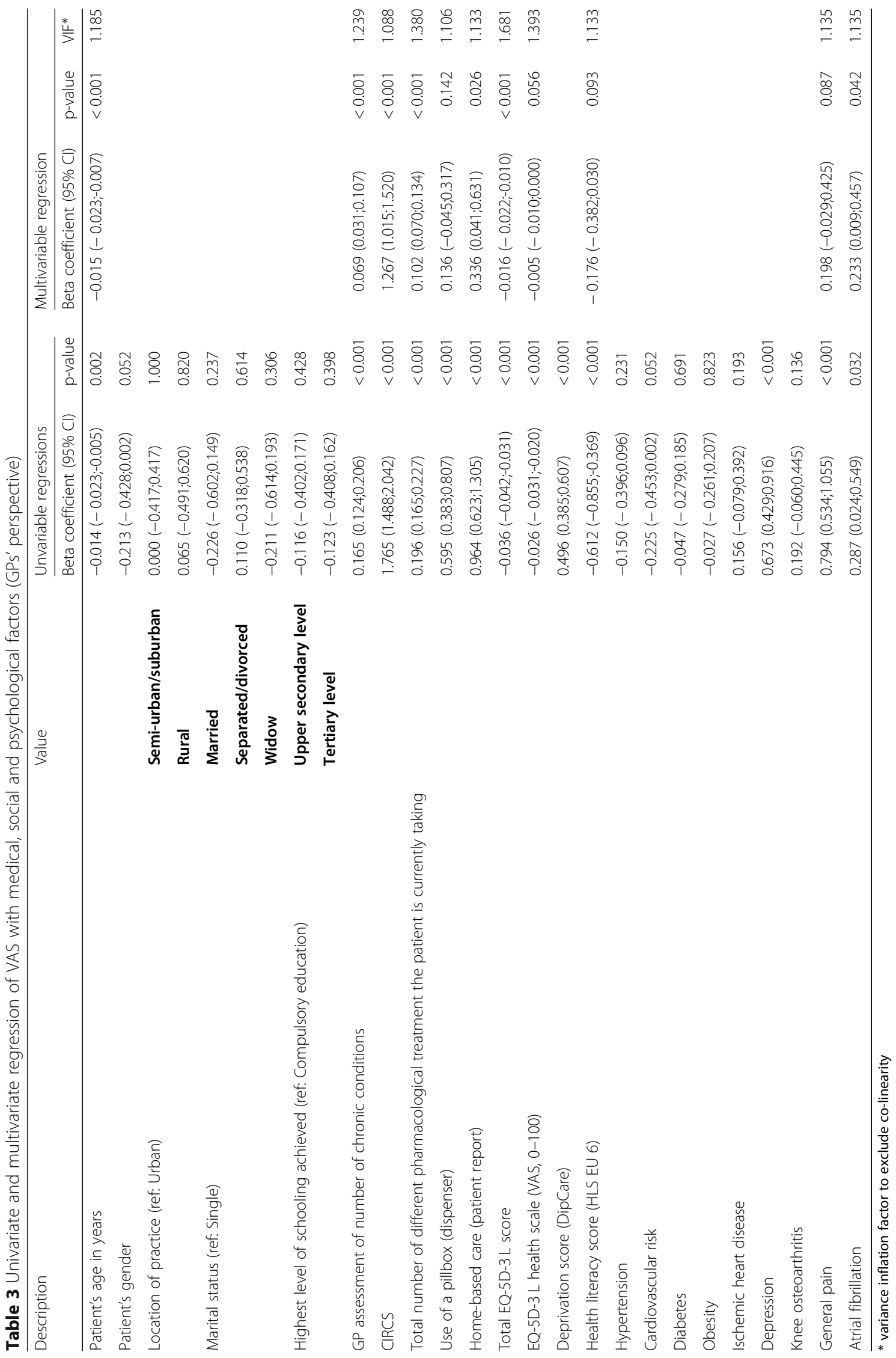




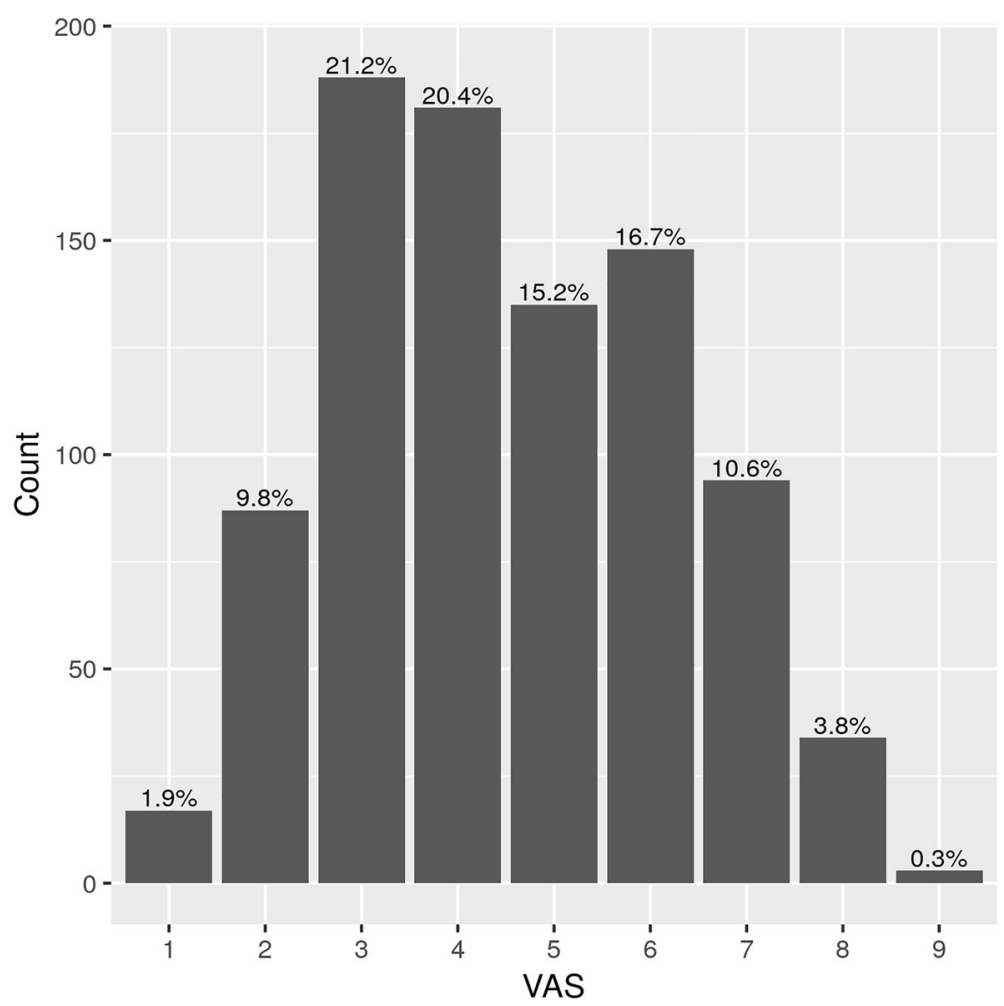

Fig. 3 VAS (GPS perspective) distribution

Whereas for patients burden of treatment is associated with socio-economic and psychological factors, GPs assessment appears to be associated with medical factors such as number or severity of chronic conditions and number of drugs. These findings offer new guidance to improve patient-centered care. Indeed, including socioeconomic and psychological factors or relying on patients' self-perception is likely to improve GPs' assessments of their multimorbid patients' burden of treatment. A more adequate estimate of this burden may help GPs weigh the benefits of any added treatment against the risk of adding to this burden thus threatening adherence to care. Further research should identify pragmatic ways of integrating the assessment of patients' burden of treatment in the routine care of multimorbid patients seen in primary care.

\section{Additional files}

Additional file 1: TBQ French and German version. (DOCX $20 \mathrm{~kb}$ )

Additional file 2: Correlation matrix. (CSV $9 \mathrm{~kb}$ )

\section{Abbreviations}

CIRCS: Cumulative illness rating scale; GP: General practitioner; PC: Primary care; TBQ: Treatment burden questionnaire; VAS: Visual analog scale

\section{Acknowledgements}

We thank the 100 participating GPs and their patients, as well as the research assistants who conducted the telephone interviews with the patients.

\section{Authors' contributions}

$\mathrm{LH}, \mathrm{DHH}$ and $\mathrm{AZ}$ developed the protocol for the MMFM study. LH, AZ, SE and $\mathrm{DHH}$ recruited the GPs. $\mathrm{LH}, \mathrm{DHH}, \mathrm{AZ}$, JP, SE planned the analysis and drafted the manuscript. JP did the statistical analyses. LH, DHH, SS, SE, SNJ and AZ contributed to interpreting the findings and the final manuscript's content. All authors read and approved the final manuscript.

\section{Funding}

This work was supported by the Swiss University Conference, project P10, which granted funding to reinforce teaching and research in primary care in Switzerland. Within the framework of this financial support, Switzerland's five university institutes of family medicine (Basel, Bern, Geneva, Lausanne and Zurich) collaborate as the Swiss Academy of Family Medicine (SAFMED). The funding source had no role in study design, data collection, analysis or interpretation, or in the preparation of the manuscript and the decision to submit the paper for publication.

\section{Availability of data and materials}

Data are available at the Family Medicine Institute of Lausanne.

\section{Ethics approval and consent to participate}

The study protocol was approved by the Human Research Ethics Committee of the Canton Vaud, acting as the lead ethics committee for Switzerland (Protocol 315/14). Each included patient gave his or her written informed consent.

\section{Consent for publication}

Not applicable.

\section{Competing interests}

The authors declare no conflicts of interest. Dagmar M Haller is a member of the Editorial Board (Associate Editor) of BMC.

\section{Author details}

'Department of Family Medicine, General Medicine and Public Health Centre, University of Lausanne, Bugnon 44, 1011 Lausanne, Switzerland. ${ }^{2}$ Centre for 
Primary Health Care, University of Basel, Basel, Switzerland. ${ }^{3}$ Institute of Social and Preventive Medicine, Lausanne University Hospital, Lausanne, Switzerland. ${ }^{4}$ Institute of Primary Health Care (BIHAM), University of Bern, Bern, Switzerland. Institute of Primary Care, University and University Hospital of Zurich, Zurich, Switzerland. ${ }^{6}$ Primary Care Unit, Faculty of Medicine, University of Geneva, Geneva, Switzerland. ${ }^{7}$ Croisettes 14, 1066, Epalinges, Switzerland.

\section{Received: 2 January 2019 Accepted: 5 June 2019}

Published online: 28 June 2019

\section{References}

1. Barnett K, Mercer SW, Norbury M, Watt G, Wyke S, Guthrie B. Epidemiology of multimorbidity and implications for health care, research, and medical education: a cross-sectional study. Lancet. 2012;380(9836):37-43.

2. Excoffier S, Herzig L, N'Goran AA, Deruaz-Luyet A, Haller DM. Prevalence of multimorbidity in general practice: a cross-sectional study within the Swiss sentinel surveillance system (Sentinella). BMJ Open. 2018;8(3):e019616.

3. Fortin M, Stewart M, Poitras ME, Almirall J, Maddocks H. A systematic review of prevalence studies on multimorbidity: toward a more uniform methodology. Ann Fam Med. 2012;10(2):142-51.

4. Condelius A, Edberg AK, Jakobsson U, Hallberg IR. Hospital admissions among people $65+$ related to multimorbidity, municipal and outpatient care. Arch Gerontol Geriatr. 2008;46(1):41-55

5. Vogeli C, Shields AE, Lee TA, Gibson TB, Marder WD, Weiss KB, et al. Multiple chronic conditions: prevalence, health consequences, and implications for quality, care management, and costs. J Gen Intern Med. 2007;22(Suppl 3): 391-5.

6. Bodenheimer T, Fernandez A. High and rising health care costs. Part 4: can costs be controlled while preserving quality? Ann Intern Med. 2005;143(1): 26-31.

7. Pifferi M, Bush A, Di Cicco M, Pradal U, Ragazzo V, Macchia P, et al. Healthrelated quality of life and unmet needs in patients with primary ciliary dyskinesia. Eur Respir J. 2010;35(4):787-94.

8. N'Goran AA, Deruaz-Luyet A, Haller DM, Zeller A, Rosemann T, Streit S, et al. Comparing the self-perceived quality of life of multimorbid patients and the general population using the EQ-5D-3L. PLoS One. 2017;12(12):e0188499.

9. Sergi G, De Rui M, Sarti S, Manzato E. Polypharmacy in the elderly: can comprehensive geriatric assessment reduce inappropriate medication use? Drugs Aging. 2011;28(7):509-18.

10. Prados-Torres A, Del Cura-Gonzalez I, Prados-Torres D, Lopez-Rodriguez JA, Leiva-Fernandez F, Calderon-Larranaga A, et al. Effectiveness of an intervention for improving drug prescription in primary care patients with multimorbidity and polypharmacy: study protocol of a cluster randomized clinical trial (multi-PAP project). Implement Sci. 2017;12(1):54.

11. Tinetti ME, Fried T. The end of the disease era. Am J Med. 2004;116(3):179-85.

12. Bayliss EA, Steiner JF, Fernald DH, Crane LA, Main DS. Descriptions of barriers to self-care by persons with comorbid chronic diseases. Ann Fam Med. 2003;1(1):15-21.

13. Russell LB, Suh DC, Safford MA. Time requirements for diabetes selfmanagement: too much for many? The Journal of family practice. 2005; 54(1):52-6.

14. Tran VT, Montori VM, Eton DT, Baruch D, Falissard B, Ravaud P. Development and description of measurement properties of an instrument to assess treatment burden among patients with multiple chronic conditions. BMC Med. 2012;10:68.

15. Boyd CM, Darer J, Boult C, Fried LP, Boult L, Wu AW. Clinical practice guidelines and quality of care for older patients with multiple comorbid diseases: implications for pay for performance. JAMA. 2005;294(6):716-24.

16. May CR, Eton DT, Boehmer K, Gallacher K, Hunt K, MacDonald S, et al. Rethinking the patient: using burden of treatment theory to understand the changing dynamics of illness. BMC Health Serv Res. 2014;14:281.

17. Eton DT, Elraiyah TA, Yost KJ, Ridgeway JL, Johnson A, Egginton JS, et al. A systematic review of patient-reported measures of burden of treatment in three chronic diseases. Patient related outcome measures. 2013:4:7-20.

18. Sav A, King MA, Whitty JA, Kendall E, McMillan SS, Kelly F, et al. Burden of treatment for chronic illness: a concept analysis and review of the literature. Health Expect. 2015;18(3):312-24

19. Rosbach $M$, Andersen JS. Patient-experienced burden of treatment in patients with multimorbidity - a systematic review of qualitative data. PLoS One. 2017;12(6):e0179916.
20. Boyd CM, Wolff JL, Giovannetti E, Reider L, Weiss C, Xue QL, et al. Healthcare task difficulty among older adults with multimorbidity. Med Care. 2014; 52(Suppl 3):S118-25.

21. van Merode T van de Ven K, van den Akker M. Patients with multimorbidity and their treatment burden in different daily life domains: a qualitative study in primary care in the Netherlands and Belgium. J Comorb. 2018;8(1):9-15.

22. Sav A, McMillan SS, Kelly F, Kendall E, Whitty JA, King MA, et al. Treatment burden among people with chronic illness: what are consumer health organizations saying? Chronic IIIn. 2013;9(3):220-32.

23. Gallacher K, May CR, Montori VM, Mair FS. Understanding patients' experiences of treatment burden in chronic heart failure using normalization process theory. Ann Fam Med. 2011;9(3):235-43.

24. Deruaz-Luyet A, N'Goran AA, Tandjung R, Frey P, Zeller A, Haller DM, et al. Multimorbidity in primary care: protocol of a national cross-sectional study in Switzerland. BMJ Open. 2015:5(10):e009165.

25. Deruaz-Luyet A, N'Goran AA, Senn N, Bodenmann P, Pasquier J, Widmer D, et al. Multimorbidity and patterns of chronic conditions in a primary care population in Switzerland: a cross-sectional study. BMJ Open. 2017;7(6): e013664.

26. N'Goran AA, Blaser J, Deruaz-Luyet A, Senn N, Frey P, Haller DM, et al. From chronic conditions to relevance in multimorbidity: a four-step study in family medicine. Fam Pract. 2016.

27. Sperber AD. Translation and validation of study instruments for crosscultural research. Gastroenterology. 2004;126(1 Suppl 1):S124-8.

28. Linn BS, Linn MW, Gurel L. Cumulative illness rating scale. J Am Geriatr Soc. 1968;16(5):622-6.

29. Perneger TV, Combescure C, Courvoisier DS. General population reference values for the French version of the EuroQol EQ-5D health utility instrument. Value Health. 2010;13(5):631-5.

30. Sorensen K, Van den Broucke S, Pelikan JM, Fullam J, Doyle G, Slonska Z, et al. Measuring health literacy in populations: illuminating the design and development process of the European health literacy survey questionnaire (HLS-EU-Q). BMC Public Health. 2013;13:948.

31. Vaucher P, Bischoff T, Diserens EA, Herzig L, Meystre-Agustoni G, Panese $F$ et al. Detecting and measuring deprivation in primary care: development, reliability and validity of a self-reported questionnaire: the DiPCare-Q. BMJ Open. 2012;2(1):e000692.

32. Buuren van S G-OK. Multivariate Imputation by Chained Equations in R. J Stat Softw. 2011;45(3).

33. Team RC. A language and environment for statistical computing. https:// wwwR-projectorg/ 2018; Version 3.5.1.

34. Brett T, Arnold-Reed DE, Popescu A, Soliman B, Bulsara MK, Fine $H$, et al. Multimorbidity in patients attending 2 Australian primary care practices. Ann Fam Med. 2013;11(6):535-42.

35. Marengoni A, Angleman S, Meinow B, Santoni G, Mangialasche F, Rizzuto D, et al. Coexisting chronic conditions in the older population: variation by health indicators. European journal of internal medicine. 2016:31:29-34

36. Muth C, van den Akker M, Blom JW, Mallen CD, Rochon J, Schellevis FG, et al. The Ariadne principles: how to handle multimorbidity in primary care consultations. BMC Med. 2014;12:223

37. Muth C, Beyer M, Fortin M, Rochon J, Oswald F, Valderas JM, et al. Multimorbidity's research challenges and priorities from a clinical perspective: the case of 'Mr Curran. Eur J Gen Pract. 2014:20(2):139-47.

38. Neuner-Jehle S, Zechmann S, Grundmann Maissen D, Rosemann T, Senn O. Patient-provider concordance in the perception of illness and disease: a cross-sectional study among multimorbid patients and their general practitioners in Switzerland. Patient Prefer Adherence. 2017;11:1451-8.

39. Deruaz-Luyet A, N'Goran AA, Pasquier J, Burnand B, Bodenmann P, Zechmann S, et al. Multimorbidity: can general practitioners identify the health conditions most important to their patients? Results from a national cross-sectional study in Switzerland. BMC Fam Pract. 2018;19(1):66

40. Shippee ND, Shah ND, May CR, Mair FS, Montori VM. Cumulative complexity: a functional, patient-centered model of patient complexity can improve research and practice. J Clin Epidemiol. 2012;65(10):1041-51.

41. Gabbay J, le May A. Mindlines: making sense of evidence in practice. Br J Gen Pract. 2016;66(649):402-3.

42. Kenning C, Coventry PA, Gibbons C, Bee P, Fisher L, Bower P. Does patient experience of multimorbidity predict self-management and health outcomes in a prospective study in primary care? Fam Pract. 2015;32(3):311-6.

43. Hudon C, Fortin M, Poitras ME, Almirall J. The relationship between literacy and multimorbidity in a primary care setting. BMC Fam Pract. 2012;13:33. 
44. Sav A, Kendall E, McMillan SS, Kelly F, Whitty JA, King MA, et al. You say treatment, I say hard work': treatment burden among people with chronic illness and their carers in Australia. Health Soc Care Community. 2013;21(6): 665-74.

45. May C, Montori VM, Mair FS. We need minimally disruptive medicine. BMJ. 2009;339:b2803.

46. Beach MC, Keruly J, Moore RD. Is the quality of the patient-provider relationship associated with better adherence and health outcomes for patients with HIV? J Gen Intern Med. 2006;21(6):661-5.

47. Tran VT, Barnes C, Montori VM, Falissard B, Ravaud P. Taxonomy of the burden of treatment: a multi-country web-based qualitative study of patients with chronic conditions. BMC Med. 2015;13:115.

48. Eton DT, Ridgeway JL, Linzer M, Boehm DH, Rogers EA, Yost KJ, et al. Healthcare provider relational quality is associated with better selfmanagement and less treatment burden in people with multiple chronic conditions. Patient Prefer Adherence. 2017;11:1635-46.

49. Al Sayah F, Majumdar SR, Williams B, Robertson S, Johnson JA. Health literacy and health outcomes in diabetes: a systematic review. J Gen Intern Med. 2013;28(3):444-52.

\section{Publisher's Note}

Springer Nature remains neutral with regard to jurisdictional claims in published maps and institutional affiliations.

Ready to submit your research? Choose BMC and benefit from:

- fast, convenient online submission

- thorough peer review by experienced researchers in your field

- rapid publication on acceptance

- support for research data, including large and complex data types

- gold Open Access which fosters wider collaboration and increased citations

- maximum visibility for your research: over $100 \mathrm{M}$ website views per year

At BMC, research is always in progress.

Learn more biomedcentral.com/submissions 